\title{
Proposal of Urban Agricultural Park Management and Operation Plan Using the Public Service Design Process
}

\author{
Sang-Mi Lee ${ }^{1 *}$, Hyung Kwon Yun², Young-Bin Jung ${ }^{3}$, and In-Kyoung Hong ${ }^{4}$ \\ ${ }^{1}$ Researcher, Urban Agricultural Research Division, National Institute of Horticultural and Herbal Science, Rural Development Administration, \\ Wanju-gun, Jeollabuk-do 55365, Korea \\ ${ }^{2}$ Senior researcher, Urban Agricultural Research Division, National Institute of Horticultural and Herbal Science, Rural Development \\ Administration, Wanju-gun, Jeollabuk-do 55365, Korea \\ ${ }^{3}$ Researcher, Urban Agricultural Research Division, National Institute of Horticultural and Herbal Science, Rural Development Administration, \\ Wanju-gun, Jeollabuk-do 55365, Korea \\ ${ }^{4}$ Postdoctoral researcher, Urban Agricultural Research Division, National Institute of Horticultural and Herbal Science, Rural Development \\ Administration, Wanju-gun, Jeollabuk-do 55365, Korea
}

\section{ABSTRACT}

Background and objective: With the revision of the Act on Urban Parks, Green Areas, Etc. in 2013, the "urban agricultural park" was newly established under the subcategory of "themed park," thereby establishing the institutional basis for the creation of urban agricultural parks. However, urban agricultural parks are still in the early stages of their introduction. There is a lack of research on direction setting and specific operation management that considers urban residents' needs and the city's physical infrastructure.

Methods: We utilized the public service design process suggested by the Ministry of the Interior and Safety of the Republic of Korea in 2019 to identify problems and develop directions for urban agricultural parks. The process consisted of the following four steps: Understanding, Discovering people's needs, Defining real problems, and Developing ideas.

Results: As four types of ideas for revitalizing urban agricultural parks, 'information users want to know,' 'user participation in design,' 'venue for local communities,' and 'urban agricultural parks as health and rest areas' were derived. This means that urban agricultural parks must provide the information users want; users must plan, decide, and implement such information by directly participating in the creation and efficient management and operation of urban agricultural parks; and urban agricultural parks must be used as a venue for local communities. Urban agricultural parks should also be spaces for health and relaxation.

Conclusion: Urban agricultural parks should avoid the unified space and passive participation patterns of existing urban parks, and become real spaces for resident participation that can satisfy all the production, leisure, landscape, ecology, and psycho-social needs of the users of urban agricultural parks. Furthermore, it is necessary to introduce a more systematic and diverse operating system so that it can work to revitalize the local community and connect organically with the function of the city.

Keywords: information, user participation, community, health, rest

\section{Introduction}

The area of urban gardens nationwide was $1,323 \mathrm{ha}$ in 2019 , an increase of $1.8 \%$ from the previous year, and the number of their users was 2.42 million, an increase of $14.2 \%$ from the previous year (EPIS, 2020). In the process of creating such a boom in urban agriculture and pursuing various projects, there has been an increasing demand for

\footnotetext{
This research was supported by the Rural Development Administration's project (PJ014385022020).

Received: January 26, 2021, Revised: February 13, 2021, Accepted: February 19, 2021

First author: Sang-Mi Lee, sangmilee@korea.kr, (1) https://orcid.org//0000-0003-1049-4705

*Corresponding author: Sang-Mi Lee, sangmilee@korea.kr, (1) https://orcid.org//0000-0003-1049-4705
} 
urban garden expansion and operation programs. In particular, the demand for creating vegetable gardens in urban parks and for programs to utilize them is increasing; in a survey of urban agricultural park users by the Rural Development Administration (2019), 95.2\% of respondents answered that it was necessary to create vegetable gardens in urban agricultural parks, and $92.2 \%$ were willing to participate in urban farming programs in such places. Urban agricultural parks are parks set up for the purpose of park-type urban agriculture pursuant to Article 8-1(1) of Act On Development And Support Of Urban Agriculture (hereinafter referred to as Urban Agriculture Act) for the hobbies, leisure, learning or experience of urban residents. Since in the Act on Urban Parks, Green Areas, Etc. (hereinafter referred to as Park and Green Areas Act), revised in March 2013, "urban agricultural parks" were newly established under the subcategory of "themed parks" installed for various purposes in addition to living-zone parks, it can be considered that the institutional foundation for the creation of urban agricultural parks was established. As of October 2020, there are about 8 urban agricultural parks nationwide, which are operated mainly by local governments: Gangdong-gu Urban Agricultural Park, Yangcheon Urban Agricultural Park, Hyangnim Urban Agricultural Park, Gwanak Urban Agricultural Park, Choansan Neighborhood Park, Jeotgae Farm Park, Hamjul Urban Agricultural Park, and Sarabong (Neighborhood) Park. However, problems with these parks that have been pointed out include poor management of the created parks, lack of budget for operation, a focus on the operation of one-off programs, and concern that the creation of urban gardens in such parks may impair the function of parks and green spaces as public goods (Rural Development Administration, 2019). In addition, despite amendments to the relevant laws, official guidelines for the creation and management of urban agricultural parks at the national and local government levels have not been prepared, and only some studies have been conducted by the private sector. For this reason, it is necessary to find a plan for the creation and efficient management of urban agricultural parks, and to form a consensus among the people about the function of public benefit of creating and operating urban gardens in the parks, including cultivation of an agricultural sentiment, creation of green space, and conservation of the environment. Urban agricultural parks can be regarded as public services under the management and operation of local governments. The Ministry of the Interior and Safety of the ROK revised, promulgated, and implemented the Enforcement Decree of the Administrative Procedure Act in 2017, which introduced the concept of "public service design" for the first time. Public service design is a new policy development technique that develops public policies and services by applying the service design method to the public sector, engaging the general public and experts directly, and communicating with them to observe and analyze public demand. (Ministry of the Interior and Safety, 2019). Therefore, this study aimed to derive an efficient management plan for urban agricultural parks as a public service by utilizing the public service design process.

\section{Research Methods}

This study utilized the public service design process suggested by the Ministry of the Interior and Safety (2019) to identify problems and derive the development directions for urban agricultural parks.

Step 1 was the stage of understanding, in which we selected a theme, formed a team, and conducted empathy activities; in the empathy activities, contextual inquiry was conducted for process sharing and urban agricultural park users, their usage hours, places, activities, methods, reasons, etc. Step 2 is the stage of discovering people's needs, in which we selected personas for the users of urban agricultural parks, drew a customer journey map for the use of urban agricultural parks, identified a positive or negative issue for each journey, and performed a service safari at Yangcheon Urban Agricultural Park, which was established in 2019 and is the newest of the urban agricultural parks. Service safari is an activity that discovers problems from the perspective of the consumer while experiencing the service first-hand (Lee G.S. 2018). Step 3 is the stage of defining real problems (pain points), where using responses to the proposition "The real problem of urban agricultural parks is $\bigcirc \bigcirc$," we created a problem-defining issue tree and defined real problems by integrating the analysis of 
the customer journey map and the contents of service safari, performed in Step 2. To solve the defined problems, we established a service direction under the proposition of " $\bigcirc \bigcirc$ should be done to revitalize urban agricultural parks" and organized this into keywords. Step 4 is the stage of developing ideas, in which we generated ideas through brainwriting according to the direction established in Step 3 , grouped the concepts of the generated ideas, and specified the contents according to each concept. Brainwriting is also called silent brainstorming, and is a quick way to come up with new ideas through writing (Lee, 2018). This step aims to generate as many ideas as possible (Rawlinson, 1981). The next step is to determine the priority for problem solving and conduct a pilot test, but this study ended up collecting as many ideas for urban agricultural park management and operation as possible and presented the results up to Step 4 in order to help those seeking to create and manage urban agricultural parks in the future. This process was conducted through a total of 5 sessions of face-to-face meetings from June to October of 2020. A professional service designer was in charge of the entire process, and the service design process is shown in Fig. 1.

\section{Results and Discussion}

\section{Step 1: Understanding}

Step 1 was the stage of understanding, which consisted of selecting a theme, forming a team, and conducting empathy activities; in empathy activities, contextual inquiry was conducted, such as process sharing and urban agricultural park users, usage hours, places, activities, methods, reasons, etc.

\section{Selecting a theme and building a team}

In Step 1, Understanding, a team was formed under the theme of "building an urban agricultural park model tailored to users." There were a total of 14 team members, including: as a representative academic, a professor with the Department of Landscape Architecture at C University; as industry experts (Urban Agriculture Manager, etc.), a representative of $\mathrm{C}$ company, an urban agricultural company, a co-chairman \& private sector representative of $Y$ Urban Farmer, and a standing representative of Dietary Life Education Y Network; as policy stakeholders who are current users of urban agricultural parks, a representative

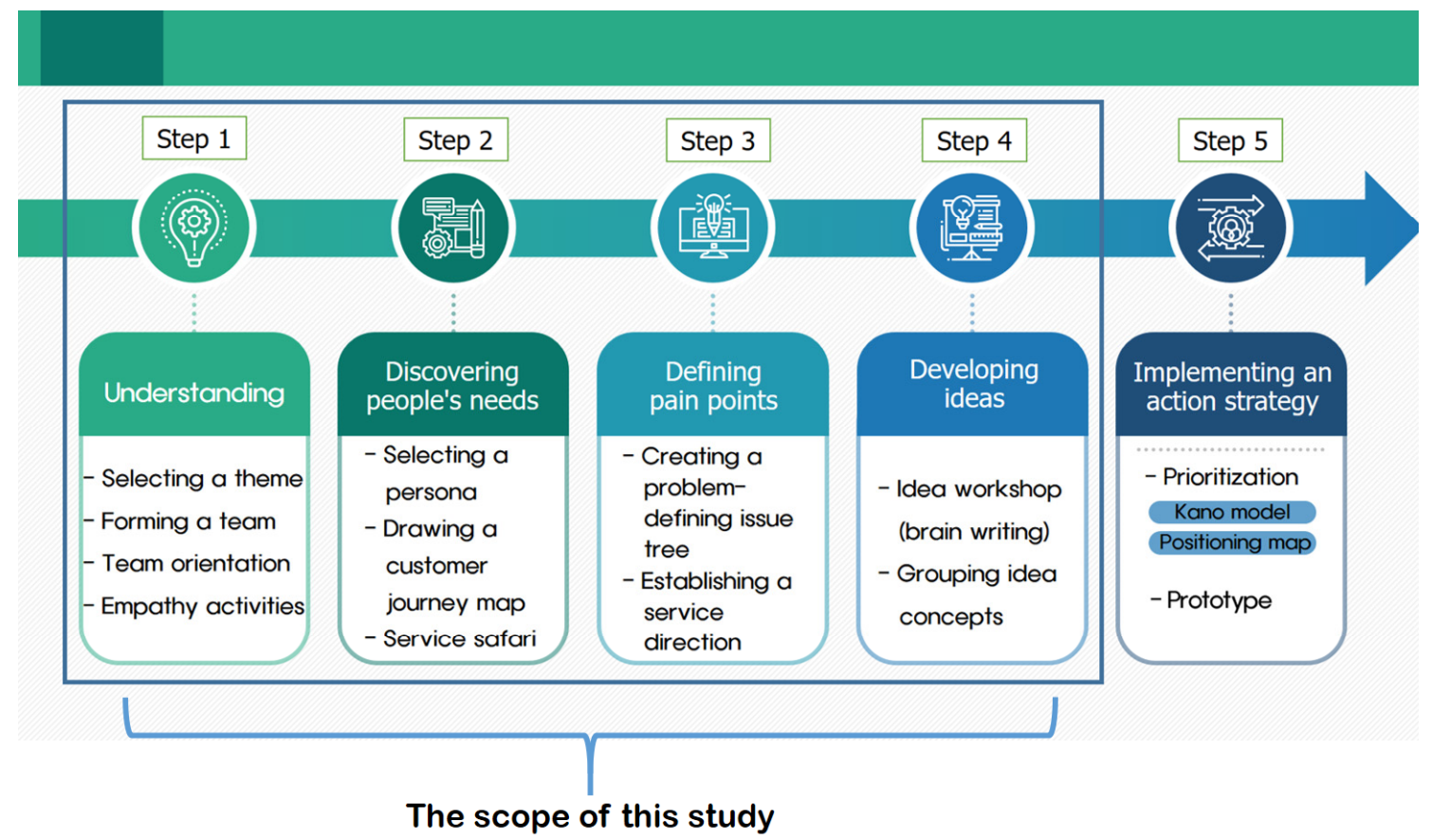

Fig. 1. Public service design process for proposal of Urban Agricultural Park Management and Operation Plan (Ministry of the Interior and Safety, 2019). 
of $\mathrm{N}$ garden community in Yangcheon Urban Agricultural Park, a parent of a child with a disability using a garden in Yangcheon Urban Agricultural Park, and a senior citizen participating in community garden activities in Nowon-gu; as policy developers, a senior agricultural researcher, two other agricultural researchers, professional researchers who are public officials belonging to the National Institute of Horticultural \& Herbal Science, Yangcheon-gu Park and Greenery Division team leader and two officials, and a service designer. The team formed in this way was called the National Design Team. The National Design Team is a policy promotion group that develops and improves public services by engaging public officials, citizens, and service designers in the overall policy process such as agenda setting, policy decision, execution, evaluation, and feedback, and using service design techniques (Ministry of the Interior and Safety, 2017).

\section{Empathy activities}

(1) Sharing

As empathy activities, the service designer generally introduced the operation of the National Design Team and service design, and the public officials from the department in charge shared the necessity and status of the urban agricultural park modelling project. Through this process, the National Design Team was able to build an understanding of the role of vegetable gardens in the parks, as well as the differences between conventional parks and urban agricultural parks, and to share the need to develop and operate appropriate spatial models and activity programs.

\section{(2) Contextual inquiry}

Contextual inquiries were conducted of urban agricultural park users, covering their usage hours, places mainly used, activities and methods of using such parks, and the reasons, and the contents can be summarized into 9 scenes. The summarized scenes are as follows: (1) A person who wants to produce healthy food grows vegetables in the garden of an urban agricultural park to provide healthy food to his or her own family; (2) A working mother moves from a bus stop to a park footpath after work and strolls aimlessly for relaxation; (3) A couple, who are college stu- dents in their twenties, are on a date, walking hand in hand in an urban agricultural park on a weekend afternoon; (4) A woman takes a walk happily with her dog on the footpath of an urban agricultural park and sits on a bench to relax on a holiday; (5) Senior citizens living alone watch TV at home on weekdays or weekend mornings, then come out to urban agricultural parks in their wheelchairs and harvest plants in the gardens; (6) A male office worker stops at an urban garden after work to harvest plants, and returns home to show his children and cook for them; (7) A person with a disability moves from their home to a park footpath in a wheelchair to exercise in the morning on weekdays, and sits in the park; 8 Kindergarteners who came out for experience activities move to the garden of an urban agricultural park as part of the class, harvest vegetables, wash them, participate in a cooking program to cook the vegetables, and share them; and (9) A retiree grows plants for harvest in the garden of a urban agricultural park on weekday mornings or holidays.

\section{Step 2: Discovering people's needs}

Step 2 is the stage of discovering people's needs, in which we selected personas of urban agricultural parks, drew a customer journey map for the use of urban agricultural parks, identified a positive or negative issue on each journey, and performed a service safari at Yangcheon Urban Agricultural Park.

\section{Selecting a persona}

Of the nine types of urban agricultural park users suggested in the contextual inquiry in Step 1, the following four types of representative users (personas) with high rationality and representativeness were selected: a family member who wants healthy food, a woman walking her dog, kindergarteners on an experience activity, a disabled woman in her 50s who takes a walk and exercises in the park.

\section{Drawing a customer journey map}

The journey for each selected representative persona and positive or negative issues for each journey were identified. 
(1) Representative Persona 1: Family member who wants healthy food

A family member who wants healthy food, one of Representative Persona 1, goes through the following journey to use an urban agricultural park: applying to use a garden $\rightarrow$ selecting a garden $\rightarrow$ receiving education for farmers $\rightarrow$ getting an allocated section of the garden $\rightarrow$ growing vegetables $\rightarrow$ harvesting $\rightarrow$ eating or donating the harvest $\rightarrow$ cleaning up the garden. In that journey, it was recognized that there was insufficient guidance on how to apply for a garden, and needs that were identified included re-education for farmers by level at any time, sharing of information on and reactions from beneficiaries of donation, and guidance on the disposal of garbage, etc.

\section{(2) Representative Persona 2: Woman walking her dog}

The journey of a woman walking her dog, Representative Persona 2, to use an urban agricultural park is as follows: check whether it is possible to bring your own dog to the urban agricultural park $\rightarrow$ prepare for a walk with the dog $\rightarrow$ go to the park $\rightarrow$ enter the park $\rightarrow$ walk with the dog $\rightarrow$ let the dog urinate/defecate $\rightarrow$ take a break $\rightarrow$ return home. On that journey, it was pointed out that it was necessary to provide a checklist and guidance for related uses to check whether companion dogs are allowed in urban agricultural parks, and post information on urban agricultural parks, such as park rules and events at the entrance. It was found that the persona hoped the following conditions would be met in the walking journey: a physical environment where she can walk happily with her dog, provision of pet products related to dog poop, etc. within urban agricultural parks, and doing gardening activities with your dog when taking a break.

\section{(3) Representative Persona 3: Kindergarteners who visit for experiential activities}

The journey of using the urban agricultural park for kindergarteners who visit for experiential activities, Representative Persona 3, included: go to kindergarten $\rightarrow$ get information on the experience program $\rightarrow$ enter the park together $\rightarrow$ enter the garden assigned to the kindergarten $\rightarrow$ harvest vegetables $\rightarrow$ play in the park $\rightarrow$ return to the kindergarten $\rightarrow$ eat snacks that incorporate the harvested vegetables $\rightarrow$ clean up. They were found to want parks to be equipped with the amenities such as signs for directions and areas within the park when entering the park together, a nameplate indicating that the garden is assigned to the kindergarten when entering an assigned garden, a shelter where they can rest during activities when harvesting vegetables, and a playground and play equipment when playing in the park.

(4) Representative Persona 4: Disabled woman in her 50s who took a walk and exercised in the park

Representative Persona 4, a woman in her 50s who came out to walk and exercise in the park, goes through the following journey: prepare for a walk $\rightarrow$ go to park $\rightarrow$ enter the park $\rightarrow$ take a walk around the park $\rightarrow$ take a break $\rightarrow$ exercise $\rightarrow$ take a break $\rightarrow$ return home. It turned out that she wants a paved road that makes it convenient for wheelchairs when going to a park, and information on events and the like in the urban agricultural park when entering the park. It was also found that she wants to rent a garden with raised-beds for the disabled when taking a walk around the park, and hopes to find a shelter space for the disabled when taking a break.

Through analyzing the journey maps of the four representative personas above, it is summarized that the following is necessary: Information, such as how to apply to use a garden; Information posted at the entrance, such as guide signs, park usage checklists, park rules, and events; Nameplates for assigned gardens; Retraining on crop cultivation, at any time; Comfortable shelter, playground, and play materials; Information on the beneficiaries of donation and by-products disposal information; A pleasant walking environment with dogs, pet products for companion dogs, an environment in which pets can participate in garden activities; A wheelchair-friendly environment, and garden rental and shelter space for the disabled.

\section{Service safari}

To experience and check the environment and facilities of urban agricultural parks, a service safari was performed at Yangcheon Urban Agricultural Park. The problems iden- 
tified were broadly divided into guidance signs, safety, rest, garden use, park management, and others. For guidance signs, there was a lack of information such as directions, zones and uses, and types of crops, and there was an opinion that information on parceling-out of gardens, activities prohibited in the park when using gardens, and garden cultivators and contact information was necessary. Regarding safety, a number of problems were found, such as slipping due to slopes and small stones of gardens and walkways, jamming due to wooden blocks placed under palm mats, jamming when moving with a shopping cart or in a wheelchair, and the possibility of eye injuries related to the installation of plant supports and stakes. In terms of rest, there was an opinion that it is desirable to have shading facilities for benches; and even though there is a shading facility, it is expected that it will be very hot due to radiant heat and reflected light, so it would be better to have facilities such as fans operated by solar power. Another opinion was that it would be desirable to provide rest facilities such as chairs in the shaded space under trees, and that it would be better if the overall promenade of the park was created with comfortable and stable elements such as trails. In addition, in the park space, there was a request to create a water space that allows visitors to soak their feet and play in the summer, making the park look cool, and to furnish chairs that let people sit to view the wet area. The use of the garden required improvement of barren fields, and furrows that made walking difficult, and passages and pavement that made it difficult to drag carts, such as shopping carts. In addition, it was stated that it is necessary to provide farming guidance to promote successful cultivation, manage plants in common cultivation spaces, and furnish irrigation facilities and management tables that can be used with high accessibility for the elderly, children, and the disabled. It was also hoped that there would be measures to prevent soil loss in vegetable gardens built on slopes, secure soil depth, ensure smooth drainage, and provide clear boundaries between gardens. On the positive side regarding the garden, it was found that plant fertilization by bees was easily performed due to the many flowers around the garden, and the garden borders and fences are made of wood, so they were evaluated as being nature-friendly and desirable for the landscape. However, there was an opinion that the use of rust-preventive finishing materials was desirable because the connection of the joints may be weakened by the rusting of steel wires binding the wood. In terms of park management, it is inconvenient to walk due to a lack of management, and the damaged landscape is neglected; If management by the park management personnel alone is insufficient, there was an opinion that it would be good to form volunteer groups that can help manage urban agricultural parks. There was a request for play areas for companion dogs, and a wider variety of plant species, in the park space. In terms of other problems, it was pointed out that the parking lot was rather narrow. Problems identified through the service safari are shown in Fig. 2.

\section{Step 3: Defining pain points}

Step 3 is the stage of defining pain points, where using responses to the proposition "The pain points of urban agricultural parks are $\bigcirc \bigcirc$ ”, we defined pain points by creating a problem-defining issue tree, and integrating the analysis of the customer journey map and the contents of service safari performed in Step 2. To solve the defined pain points, we established a service direction under the proposition of " $\bigcirc \bigcirc$ should be done to revitalize urban agricultural parks" and organized this into keywords.

\section{Creating a problem-defining issue tree}

A problem-defining issue tree was created using responses to the proposition, "A pain point of urban agricultural parks is $\bigcirc \bigcirc$." These were summarized as follows based on a total of 74 opinions: lack of guidance and signs, and information such as introduction and explanations; insufficient information and promotion on parceling-out of gardens; lack of safety management; lack of education related to cultivation; lack of ease of use; lack of sense of community; lack of rest areas and things to see and enjoy; no mandatory donation or feedback on donations; lack of connection between park and its gardens; and low traffic accessibility (Table 1). By integrating this tree with the content of the service safari and the analysis of the customer journey map performed in Step 2, we defined the following pain points of urban agricultural parks: (1) Lack of in- 


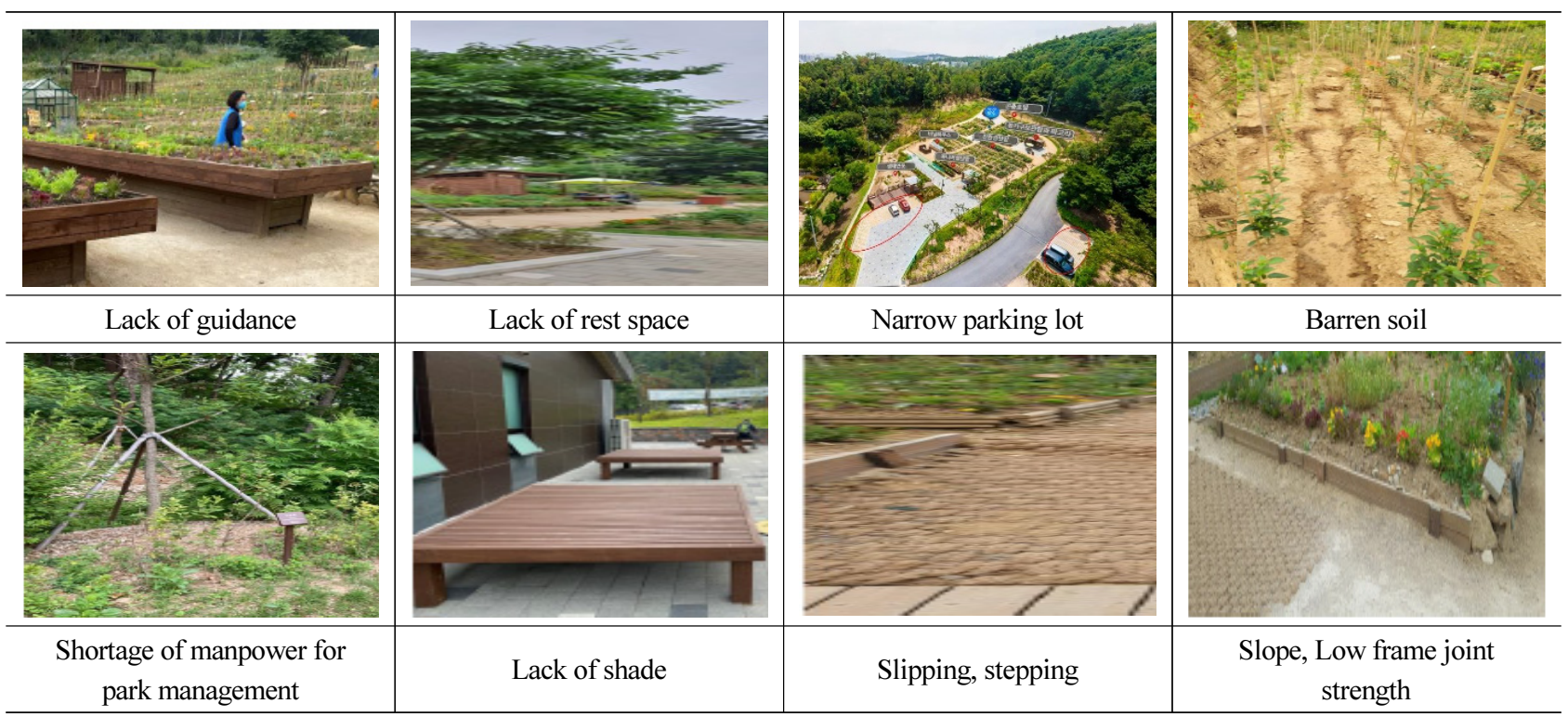

Fig. 2. Problems of urban agricultural park environment and facilities discovered through service safari.

Table 1. Opinion and classification of problems in urban agricultural parks

\begin{tabular}{|c|c|c|}
\hline Classification & Opinion & Frequency \\
\hline Lack of guidance and signs & $\begin{array}{l}\text { Lack of entrance/exit guidance; park entrance/exit guidance, road warning signs required; } \\
\text { directions }\end{array}$ & 4 \\
\hline $\begin{array}{l}\text { Lack of information such as } \\
\text { introduction and explanation }\end{array}$ & $\begin{array}{l}\text { Lack of information; excluding an information panel (pamphlets), there was no } \\
\text { introduction of gardens, lack of explanation of paddy fields and swamps in the park; no } \\
\text { name and description of side roads, etc. or information for each theme }\end{array}$ & 9 \\
\hline $\begin{array}{l}\text { Insufficient information } \\
\text { and promotion on } \\
\text { parceling-out of gardens }\end{array}$ & $\begin{array}{l}\text { No information on when gardens are parceled out; difficulties in applying to use the garden; } \\
\text { information on how to parcel a garden out, how to apply for use, and related to parceling-out } \\
\text { for communities }\end{array}$ & 5 \\
\hline Lack of safety management & $\begin{array}{l}\text { Downhill/uphill, drainage, negligence in management, cleaning, need to install traffic lights } \\
\text { on the driveway at park entrance, anti-slip bumps, slope way, slope }\end{array}$ & 8 \\
\hline $\begin{array}{l}\text { Lack of education related } \\
\text { to cultivation }\end{array}$ & $\begin{array}{l}\text { Lack of farming education; lack of cultivation education, management education, } \\
\text { combination of production and learning; lack of understanding and management of crops, } \\
\text { economic feasibility, harvest not proportional effort }\end{array}$ & 7 \\
\hline Lack of ease of use & $\begin{array}{l}\text { Inconvenient to access water; water supply, toilet, watering, humus boxes, drinking } \\
\text { fountain, information board, soil barrenness; bench lacked shade, lack of benches, presence } \\
\text { of mosquitoes and insects }\end{array}$ & 12 \\
\hline Lack of sense of community & $\begin{array}{l}\text { Need for community spirit (caring, sharing, emotional communion), a sense of belonging of } \\
\text { users, no friends (co-workers) to work with; rules of use; lack of civic consciousness. }\end{array}$ & 5 \\
\hline $\begin{array}{l}\text { Lack of rest area and } \\
\text { things to see and enjoy }\end{array}$ & $\begin{array}{l}\text { Need for related cultural events, various user needs, lack of things to enjoy, need for } \\
\text { revitalization of fun community gathering events, summer fountain, no attractive points, no } \\
\text { unique feature, no theme, lack of things to see, no play space, no park programs, no } \\
\text { programs by period, the need for planting plan to create an attraction, limited plant species, } \\
\text { several types of distracting pavement }\end{array}$ & 15 \\
\hline $\begin{array}{l}\text { No mandatory donation and } \\
\text { feedback on donations }\end{array}$ & Guidance on how to donate, mandatory donation required & 2 \\
\hline $\begin{array}{l}\text { Lack of connection between } \\
\text { parks and gardens }\end{array}$ & $\begin{array}{l}\text { Need to connect park with its gardens; separation of the park trails and the gardens; need to } \\
\text { harmonize park with its gardens; need to connect with the forest at the edge of the park }\end{array}$ & 4 \\
\hline Low traffic accessibility & Inconvenient transportation, connection to the city center, parking & 3 \\
\hline
\end{tabular}


formation and guidance signs, (2) Lack of information such as event guidance, theme introduction, and explanation, (3) Insufficient information and promotion on parceling-out of gardens, (4) Lack of safety and management, (5) Lack of education, (6) Lack of convenience in using facilities, (7) Lack of sense of community, (8) Need for rest area and shelter improvement, (9) Lack of things to see and enjoy, (10) No mandatory donation or feedback on donations, (11) Lack of connection between a park and its gardens, (12) Difficulty in participating with companion dogs, (13) Lack of gardens and shelters for the disabled, and (14) Low traffic accessibility.

\section{Establishing a service direction}

To establish a service direction, a total of 82 opinions were obtained on the proposition, "○○९ should be done to revitalize urban agricultural parks"(Table 2). Those opinions were summarized as follows using the issue tree: provision of information such as guidance signs; online sharing channels for users; notification service for items such as promotions; user education (awareness, usage, cultivation methods, etc.); systematic management plan; professional management of gardens and parks; development of various programs; community activation; diversification of gardens; harmonization of park with its gardens; attractions in the park; various methods for parceling-out of gardens; establishing a safe passage plan; sharing of donation-related operations. The key words were derived according to the established direction, such as (1) Information provision (guidance, direction signs), (2) Sharing platform, (3) Creation and management plan, (4) Convenience of use and accessibility, (5) Garden education, (6) Community activation, (7) Program, (8) Donation (9) Harmonization of a park and its gardens.

\section{Step 4: Developing ideas}

Step 4 is the stage of developing ideas, in which we generated ideas through a brainwriting based on the direction established in Step 3, grouped concepts of the generated ideas, and specified the contents according to each concept. Brainwriting is also called silent brainstorming, and it is a way to come up with ideas by communicating in writing (Lee, 2018). This step aims to generate as many ideas as possible, and four types of ideas were derived, including information users want to know, user participation in design, a venue for local communities, and urban agricultural parks as a health and rest space. The concrete ideas were as follows.

\section{Grouping 1: Information that users want to know}

The first group of ideas for revitalizing urban agricultural parks is "information users want to know," which means that urban agricultural parks should provide the information that users want. The methods can be categorized into plant-markers, park guides, illustrated guides to park plants, and farmers' almanac services.

\section{(1) Plant-markers}

Plant-markers basically mean plant name tags, which can be produced and used as a QR code that includes detailed information, such as characteristics of plants, and cultivation methods. In addition, since the branding to create a park name can be also included in the content of plant-markers, the opinion was presented that it is important to give a name that contains the park's story, and inform users of such contents.

(2) Park guides

The opinion was given that 'park guides' includes the entrance sign, the large symbolic sign for the access road, and guidance such as other signs, symbols or craft items installed to help find the way, and recommended courses in a park. To provide various information more efficiently, it is effective to visualize information such as analog pictograms, infographics, maps, diagrams, photos, and illustrations. In addition, it would be desirable to have Braille guide boards for the visually impaired.

\section{(3) Illustrated guides to park plants}

Illustrated guides to park plants are booklets or brochures that organize seasonal information on plants planted in a park and its garden in connection with urban agricultural park users' education and field trips. The opinion was given that it is desirable to provide such guides. Existing specialized materials can be used as illustrated guides, or illustrated guides created by the participants can be displayed 
Table 2. Opinion and classification on the service direction in urban agricultural parks

\begin{tabular}{|c|c|c|}
\hline Classification & Opinion & Frequency \\
\hline $\begin{array}{l}\text { Provision of information } \\
\text { such as guidance signs }\end{array}$ & $\begin{array}{l}\text { Posting of information, explanatory signs, detailed information to increase connection, } \\
\text { description of thematic plants }\end{array}$ & 4 \\
\hline $\begin{array}{l}\text { Online sharing } \\
\text { channels for users }\end{array}$ & $\begin{array}{l}\text { Easy application for usage through public portal sites, search all gardens information in one } \\
\text { place, sharing channels for users, quick information sharing through instant messenger, } \\
\text { establishing a notification channel, notification via social media }\end{array}$ & 6 \\
\hline $\begin{array}{l}\text { Notification service } \\
\text { such as promotion }\end{array}$ & Preparation of public relations plans, public relations/notification services, active publicity & 3 \\
\hline $\begin{array}{l}\text { User education (awareness, } \\
\text { usage, cultivation methods, etc.) }\end{array}$ & $\begin{array}{l}\text { Education for all users, building an eco-friendly education system for users, user education } \\
\text { and evaluation in the first and second half, education on cultivation and community spirit }\end{array}$ & 4 \\
\hline Systematic management plan & $\begin{array}{l}\text { Convenient water management, garden drainage ditch reorganization, maintenance of water } \\
\text { supplies and utilization systems, soil management, garbage dump management, } \\
\text { compost/fertilizer, production space, measures to prevent crop theft, expansion of human } \\
\text { and material resources for park management, securing manpower for landscape management }\end{array}$ & 10 \\
\hline $\begin{array}{l}\text { Professional management of } \\
\text { gardens and parks }\end{array}$ & $\begin{array}{l}\text { Arrangement of professional managers, recruitment of professionals, volunteer workday of } \\
\text { garden users }\end{array}$ & 3 \\
\hline $\begin{array}{l}\text { Development of } \\
\text { various programs }\end{array}$ & $\begin{array}{l}\text { Lack of community programs; target-specific (short-to-long term) program development; } \\
\text { period-specific (short-term, one-off programs) events; park program activation; course } \\
\text { development; experience programs, experience services; farmer's market; separate } \\
\text { operation of learning experiences, its own event using garden crops; insect experience } \\
\text { center; play materials for children }\end{array}$ & 13 \\
\hline Community activation & $\begin{array}{l}\text { Community events, indoor/outdoor cooking space installation (regulation revised), shared } \\
\text { cooking space, shared cooking, ready-to-eat vegetables, information sharing to revitalize the } \\
\text { community, time to get to know neighbors, spatial facilities that enable connecting } \\
\text { production and learning, community room (space) assignment }\end{array}$ & 8 \\
\hline Diversification of gardens & $\begin{array}{l}\text { Vegetables and flowers, variety of species, variety of seedlings, planting flowers around } \\
\text { gardens, reinforcing vegetation at the edge of the park forest, preserving ecosystems, } \\
\text { creating seasonal themed parks, various planting patterns, plant diversity, revitalizing garden } \\
\text { design by user type, attempt to make changes related to information and plans }\end{array}$ & 11 \\
\hline $\begin{array}{l}\text { Harmonization of a } \\
\text { park and its gardens }\end{array}$ & $\begin{array}{l}\text { Gardening activities in parks, harmonious garden design, tour programs that tour both a park } \\
\text { and its gardens at once, creating a landscape garden around vegetable gardens (a garden that } \\
\text { can be hanging out), guerrilla gardens using the slopes }\end{array}$ & 5 \\
\hline Attractions in the park & Key attractions, attractive garden and shelter creation & 2 \\
\hline $\begin{array}{l}\text { Various methods for } \\
\text { parceling-out of gardens }\end{array}$ & $\begin{array}{l}\text { Diversification of selection methods of garden users, enactment and amendment of } \\
\text { ordinances on parceling-out in urban agriculture }\end{array}$ & 2 \\
\hline Establishing a safe passage plan & Vehicle traffic management, roadway safety, road management, CCTV installation & 4 \\
\hline $\begin{array}{c}\text { Sharing of donation-related } \\
\text { operations }\end{array}$ & $\begin{array}{l}\text { Receiving opinions from beneficiaries of donation (reviews, feedback), disclosure of } \\
\text { donation details, donation ledger, highlighting top donors, stalls for voluntary donation, } \\
\text { unmanned sales stands, donation boxes }\end{array}$ & 7 \\
\hline
\end{tabular}

and provided, by planning a program to produce a new one. In connection with this, a plant quiz contest can be held, and an open library can be operated by receiving donations of various publications from local residents.

\section{(4) Farmers' almanac}

It is required to provide a farmers' almanac that includes farming-related information, such as weather, temperature, and pest control, seasonal crops, and cultivation method. This can be provided through a smart phone or a PC, by constructing a year-round schedule such as parceling-out of gardens and events in the form of digital data and creating an online platform such as a kiosk or smart application. The kiosk can be installed and operated using solar power, 
and the digital farmers' almanac can be offered in conjunction with the illustrated guides to park plants.

\section{Grouping 2: User participation in design}

The second group of ideas for revitalizing urban agricultural parks is "user participation in design," which means that the creation and efficient management and operation of urban agricultural parks should be planned, decided, and executed through the direct participation of users. This is in keeping with the findings of Yun and Cho (2012) that urban agricultural parks need to be approached from a physical and content perspective in which resident participation can be actually realized, through a new model of a forward-looking urban park that requires resident participation. The methods of user participation in design derived in this study come down to establishing standard user regulations and operating a coordinator system in urban agricultural parks.

\section{(1) Establishing standard user regulations}

Standard user regulations refer to rules for garden users in urban agricultural parks, which include enacting terms and conditions for the parceling-out and use of gardens, writing a pledge related to use such as the use of eco-friendly materials, and imposing a penalty for the violation of such rules. It will be necessary to provide a checklist for garden use etiquette when accompanied by a dog; to have a certain amount of garden usage fee paid; and to establish on- and off-line outlets that members such as administrators, managers, users, and educators can share so that the contents and time of compulsory volunteering can be set and managed on the system. For a garden usage fee, Yoon (2020) reports that if the cost is calculated by reflecting the size of the garden, and if agricultural education and various experience programs are included, it will not be burdensome to users to ask for a payment in the range of 10,000 to 40,000 won/year. It is considered that such payment can encourage participation and management by forming an emotional attachment among users to the space (Oh, 2012).
(2) Operating a coordinator system in urban agricultural parks

If the manpower that manages urban agricultural parks is called a coordinator, it is necessary to hire full-time management specialists or to organize a volunteer group and a civic management group. In addition, docents can be employed to guide visitors and explain urban agricultural parks. Oh (2012), Keum (2013) and others suggested plans to link urban agricultural park management with job creation for the elderly. It would also be possible to create jobs for various vulnerable social groups and utilize nationally nurtured professionals such as urban agricultural managers as coordinators. By introducing "agriculture" into the urban space, "productive codes" are combined with the consuming city, recalling the importance of the "primary industry" and expanding the pluralistic values of agriculture and rural areas (Kwon et al., 2003) to the city; and in the process of expanding the pluralistic values of agriculture and rural communities (Kwon et al., 2003) to urban areas, the role and cooperation of agricultural and rural experts can be requested (Yun and Cho, 2012).

\section{(3) Other}

As other management measures, there were suggestions to establish rainwater utilization facilities, composting facilities, or a seed distribution and return system (seed library), and to introduce an open greenhouse that can serve as a community botanical hospital.

\section{Grouping 3: A venue for local communities}

The third group of ideas for revitalizing urban agricultural parks is "a venue for local communities," which means that urban agricultural parks should be used as a venue for local communities, and the methods by which this can occur are organized into education, programs, community communication, and sharing. As urban agricultural parks are spaces for all park users, it is necessary to develop and operate various use programs, and to prepare various measures which harmonize participants and non-participants in garden cultivation within the parks through education and promotion, in order to maintain the public nature of such parks (Nam et al., 2015). In addition to promoting 
mutual exchanges such as within small groups of participants in gardening, based on vegetable gardens in the parks, through programs that allow park users to participate together, such as a harvest-sharing festival, an operation and management plan should be explored for the garden to go beyond the role of a place where crops are cultivated, to a place of mutual exchange where participants in gardening and park users communicate with each other (Park, 2012).

\section{(1) Education}

Various education programs can be provided in urban agricultural parks, and these can be conducted by season, by age (Kid/ youth/ adult farmers, etc.), by class (introductory/ advanced/ conquest), and according to demand (general/ expert). Agricultural-related job experiences and career search activities can also be provided for adolescents. The content of education can encompass a wide variety of fields, such as plants, seeds, gardening, landscaping, dietary life, environment, ecology, and insects. For education, it is necessary to have educational places such as indoor training grounds and outdoor greenhouses, and to install the related facilities and systems to enable real-time online training to respond to the COVID-19 pandemic situation.

\section{(2) Programs}

To serve as a venue for a local community, various programs are needed, ranging from one-off short-term experiences to festival-type programs. It was argued that it is important to raise the level of ecological awareness among urban residents through the development of public programs that allow a broad segment of the general public to participate (Nam et al., 2015), and the operation of various experience programs for each growth period of crops (Yoon \& Cho, 2012). The operation of such urban garden programs can have an impact on participants' mutual exchange and sense of community (Park, 2012). In addition, to carry out such programs, it is necessary to create an experience center in which activities can be performed according to the characteristics of each program and target (Jang, 2013).

\section{(a) One-off short-term experience programs}

One-off short-term experience programs can be planned, including a "Tree-planting Day" in which various crops such as potatoes and sweet potatoes are planted or propagated, or flowerpots are distributed for free or sold, or flowers are planted in villages in connection with Arbor day events; a "Harvest Day" on which you can harvest various crops such as potatoes, sweet potatoes, herbs, and vegetables; a "Cooking Day," including farm chef events using harvested crops or plant materials in urban agricultural parks, using mobile shared kitchen trucks, sharing recipes for cooking harvests, or 'Shall we have dinner together?' - shared meals with single-person households; a "Craft Work Day", in which you can complete various craft works such as soap-making, air freshener making, pressed flowers, woodworking, dyeing, by introducing the concepts of recycling and upcycling; "Companion Day," featuring companion plant sales and related education, making snacks for companion animals, pet show, fun festival for pets; and "Sale Day," where you can sell and donate garden crop dishes, craft works, etc. such as plants/flowerpots bazaar and flea market.

\section{(b) Festival-type programs}

The festival-type program is aimed at local urban agricultural fairs, and can feature various cultural and artistic performances, including: education and workshops on specific subjects, as well as one-off short-term experience programs suggested above including drawing plants, drawing contests, viewing nature-related movies, photography exhibitions, exhibitions of illustrated poems, exhibitions of artists related to nature (ecology), musical concerts, and poongmulnori such as rituals related to agriculture. As additional events, stamp tours, linking farmers to marketplaces, exhibitions and sales of agricultural equipment, and awards ceremonies are suggested; sharing of seeds and flowerpots and a top donor awards ceremony can be planned. In operating such a festival-type program, it is desirable that the department in charge from local government, urban agriculture-related communities, and those in charge of parceling out the gardens participate and share the role.

(c) Programs by special target

In terms of programs for special targets, it was suggested 
that education, healing, and treatment programs could be planned and operated for the physically handicapped, mentally handicapped, the elderly, women and men, mothers and fathers, and multicultural families. In particular, the purposes of such programs were found to be diverse, and could include muscle and joint exercise, food cost savings, relief of feelings of isolation, emotional stability such as relief of depression/anxiety, and social adaptation. Recently, horticultural therapy and care farming are being highlighted, and programs for specific targets planned in urban agricultural parks can be carried out in conjunction with such specialized programs and experts.

\section{(3) Community communication}

For community communication, it is necessary to establish an online app and SNS in connection with the farmers' almanac, provide announcements and related information on parceling-out of gardens, provide support to enable those involved in the parceling-out to communicate, and offer information related to service programs of national and local governments. It would also be necessary to provide a space to support the various community gatherings formed in urban agricultural parks. An indoor facility that can function as a simplified cooking space or cafeteria to enable cooking and sharing of garden products, or an outdoor space in harmony with nature could be considered. Oh and Park (2015) also proposed food and beverage spaces and multi-purpose spaces as facilities to be introduced to urban agricultural parks, and Oh (2012) also reported on the need to provide cooking spaces to form a community through meals in urban agricultural parks. However, the current law prohibits cooking in parks, with violators subject to a fine of 100,000 won under the Park and Green Areas Act. In this regard, to install cooking spaces in urban agricultural parks, a policy proposal is needed to add "barbecue facilities (including water supply support and dishwashing facilities)" to recreational facilities in urban agricultural parks under the Enforcement Decree of the Act On Urban Parks, Green Areas, Etc.

\section{(4) Sharing}

For sharing in urban agricultural parks, donations can be required by setting a certain percentage of garden crops or number of donations; and refrigerators and unmanned stalls for donating crops can be introduced, and a donation board set up to check donors, donation beneficiaries, and feedback from donation beneficiaries. Through a "Donation Thermometer" that displays the donation status, additional points can be given to donors in future parceling-out of gardens through the selection of top donors and the introduction of an additional point system for donors. Community events in which processed products such as kimchi are made using the garden harvests and then donated can also be planned. A study by Yoon (2020) suggested that it is desirable for garden users to consume some of their crops and share the rest with the local community. Lee \& Kwon (2017) proposed the introduction of an open market, but this could be operated in the form of unmanned stalls based on donations as mentioned above. In addition, the creation of a common garden area dedicated to education, experience, and donation was suggested. Yoon (2012) argued that urban agricultural parks are a process and method of restoration for good communities, and for them to be utilized as a medium for making a good neighborhood, a common orchard or garden should be created.

\section{Grouping 4: Urban agricultural parks as a health and rest space}

The fourth group of ideas related to revitalizing urban agricultural parks is "urban agricultural parks as a health and rest space," meaning that urban agricultural parks should be spaces for health and relaxation; the methods were summarized into shelters, walking trails (dulle-gils), universal design, and the creation of a children's playground.

\section{(1) Shelters}

Spaces such as shade and ecological natural shelters should be provided to allow park or garden users to enjoy experiential activities and relax together. According to Lee \& Kwon (2017), deck shelters, pergolas, and trellises can be arranged as rest and leisure facilities that offer a scenic view. If there are many users, it may be possible to consider establishing a system such as reservation for use.

(2) Walking trails (dulle-gils)

Walking trails that can harmoniously connect a park with 
its gardens need to be created, and guides provided on the trails. It is also desirable to include elements of scenery, aesthetics and fun in urban agricultural parks, install lighting to allow users to enjoy such parks even at night after work, and build gardens by crop or theme so users can feel the seasonal changes. A space needs to be created where users can take a break intermittently while walking throughout long walking trails. Yoon (2020) argued that urban agricultural parks should be used both as agricultural landscape resources and as complex resources through the introduction and application of various agricultural products that are comparable to ornamental plants.

\section{(3) Universal design}

Universal Design is a concept of designing products or facilities that can be used conveniently regardless of the user's physical size, ability, activity, or age; this has been known primarily as a design concept to support the socially underprivileged (Kim, 2020). Yoon (2020) reported that a space where all park users can participate and enjoy should be planned, as the majority consider that the gardens in a park are a space for "all park users." Therefore, in urban agricultural parks, not only gardens and facilities for general users, but also shelters and barrier-free walkways for wheelchair users should be created; and raised beds that apply universal design should be installed so that users with physical disabilities can participate in garden activities. It would be desirable to provide a cultivation space that applies such a universal design, by setting a rule to allocate a certain percent of the total cultivation area in consideration of the ratio of the disabled to the total population of the region.

\section{(4) Children's playground}

Jung et al. (2013) reported that "children under the age of 13" was the largest group in urban parks in terms of the age group subject to urban agriculture, while "family" was the largest class. In addition, the Representative Personas 1 and 3 in Step 2 of this study were a family member who wants healthy food, and kindergarteners who had an experience activity. Based on these findings, it is necessary to provide a safe children's playground in nature that children, the representative persona of urban agricul- tural parks, can enjoy. It would be desirable to have play areas that children can use in each season, such as forest play, water play, and sledding slope, as well as a space where guardians can watch the children. The arrangement of safety personnel and volunteers so that children can play safely while guardians are engaged in garden activities should also be considered.

\section{(5) Other}

With regard to other matters, the convenience of use can be improved by installing mobile phone chargers or lockers that can store garden users' belongings while they are engaged in garden activities.

\section{Conclusion}

Urban agriculture, which has been growing mainly in urban idle spaces, rooftops, and weekend farms, has led to a move to introduce agricultural parks in scenic greenbelts close to urban residential areas or in areas where residential land development projects are being promoted to meet the needs of urban residents. In particular, the demand for garden creation and utilization programs is increasing within urban parks. As "urban agricultural parks" were newly included as a sub-category of "themed parks" in the Park and Green Areas Act, revised in March 2013, it can be considered that the institutional foundation for the creation of urban agricultural parks was established. However, urban agricultural parks are still in the early stages of their introduction, and there is a lack of research on the establishment of direction and specific operation management considering the needs of urban residents and physical infrastructure of cities. This study utilized the public service design process to identify the problems with and derive efficient operation plans for urban agricultural parks; and the process consisted of four steps: Understanding, Discovering people's needs, Defining the real problems, and Developing ideas. As a result, four types of ideas for revitalizing urban agricultural parks were derived: "information users want to know," "user participation in design," "venue for local communities" and "urban agricultural parks as health and rest areas." This means that urban agricultural parks should 
provide the information that users want, and allow users to plan, decide, and implement such information by directly participating in the creation and efficient management and operation of such parks, while serving as a venue for local communities and as a space for health and rest.

Urban agricultural parks should be spaces for resident participation in the true sense that can satisfy all the needs of users in terms of production, leisure, scenery, and ecology, and from the psychosocial perspective, by avoiding the provision of uniform space for the passive participation of users found in existing urban parks. Furthermore, such parks would be required to introduce a more systematic and diversified operating system so that they can be organically connected with urban functions by contributing to revitalizing local communities.

The findings of this study have significance in that they propose an efficient management and operation plan for urban agricultural parks by utilizing the public service design process. As it was carried out with the support of the Rural Development Administration's pilot research project, it is expected to be used as basic data to present guidelines for the creation, management and operation of urban agricultural parks at the national and local government level. However, there was a limit to our ability to gather the opinions of all those related to urban agricultural parks from all walks of life, as it was focused on Yangcheon Urban Agricultural Park, and involved a small number of the National Design Team members. Therefore, it is considered that follow-up studies should be conducted on the issues to be supplemented, amended, or added based on the findings of this study.

\section{References}

Jang, S.S. 2013. Composition and application for thema garden in urban agriculture experience -Focused on Cheongju Munam ecological park-. Master's thesis, Dankook University, Chenan, Korea.

Jung, S.J., S.M. Lee, J.H. Moon, Y.J. Lee, and Y.J. Song. 2013. Analysis of the preference and needs of urban agriculture-related activities of urban park users. J. Korean Soc. People Plants Environ. 16(4):217-225. https://doi.org/10.11628/ksppe.2013.16.4.217

Keum, S.G. 2013. The start of urban agriculture activation in Busan, urban agricultural park. BDI policy focus. 196:1-12

Kim, M.Y. 2020. Development of work uniform design for people with disabilities applying a universal design concept. Res. J. Costume Cult. 28(3):344-355. https://doi. org/10.29049/rjcc.2020.28.3.344

Kwon, O.S., D.H. An, and S.W. Lee. 2003. Multifunctionality of agriculture, congestion costs, preserving agricultural production and rural community. Korean J. Agric. Econ. 44(1):153-173.

Korea Agency of Education, Promotion and information Service in Food, Agriculture, Forestry and Fisheries (EPIS). 2020. 2019 Urban agriculture status. 2020-02-03. Retrieved from https://www.modunong.or.kr:449/contents/bbs/bbs View.do?menuNo=41\&bbsId=1150\&bbsSeq $=18 \&$ pageI ndex $=1 \&$ pageUnit $=10 \&$ searchCondition $=$ all\&searchKe yword $=$

Lee G.S. 2018. A Study on the improvement of public service process using service design : Focusing on the citizen design groups. Doctoral dissertation, Inha university, Incheon, Korea.

Lee J.I. and J.W. Kwon. 2017. Strategy and basic planning for creating an urban agricultural park-focusing on Gosangol village in Daegu city. J. Korean Inst. Landsc. Archit. 45(4):23-34. https://doi.org/10.9715/KILA.2017. 45.4.023

Ministry of the Interior and Safety. 2017. The Manual of Participatory Public Service Design Group 2017. Seoul, Korea: Author. Retrieved from https://mois.go.kr/frt/sub /a06/b02/govServiceDesign/screen.do

Ministry of the Interior and Safety. 2019. Easy-to-understand public service design, Government Service design guide. Sejong, Korea: Author. Retrieved from http://kidp.or.kr/ index.html?menuno $=1132 \&$ bbsno $=15151 \&$ boardno $=62$ 2\&ztag=rO0ABXQAMzxjYWxsIHR5cGU9ImJvYXJkI iBubz0iNjIyliBza2luPSJraWRwX2JicyI\%2BPC9jYWx sPg\%3D\%3D\&siteno=16\&act=view

Nam K.H., S.Y. Kim, E.J. Kang, and Y.G. Kim. 2015. Public park awareness along with community garden cultivation participation within an urban park. J. Korean Inst. Landsc. Archit. 43(1):120-131.

Oh, J.N. and H.S. Park. 2015. A study on the complex 
building planning for urban agriculture including the program and space characteristics to activate the local community. J. Korean Living Environ. Syst. 22(3):357-368. https://doi.org/10.21086/ksles.2015.06.22.3.357

Oh G. 2012. A Study on the development of urban agricultural park model. Local Administration Policy Research. 2(2):85-105.

Park, H. 2012. A study on the implications from the modern large park planning and the features. J. Reg. Assoc. Archit. Inst. Korea. 14(3):63-74.

Rawlinson, J.G. 1981. Creative thinking and brainstorming. New York, U.S.A: Wiley.

Rural Development Administration. 2019. Horticultural research annual report: Development of public urban community garden model and management technology for community revitalization. Wanju, Korea: Author. Retrieved from https://www.ntis.go.kr/project/pjtInfo.d o?pjtId=1395061974\&pageCode $=$ TH_TOTAL_PJT_D TL

Yun H.J. and M.K. Cho. 2012. The consideration of progressive urban park and the possibility of urban agricultural park. J. Korean Soc. Rural Plan. 18(2):81-90. https://doi.org/10.7851/ksrp.2012.18.2.081

Yoon J.H. 2020. Survey on recognition of urban agricultural park by neighborhood park users. Master's thesis, Gyemyung university, Daegu, Korea. 